\title{
Prevalence of Hymenolepis nana in Indigenous Tapirapé Ethnic Group from the Brazilian Amazon
}

\author{
Antonio F. Malheiros ${ }^{1,5, *}$, Patrick D. Mathews ${ }^{2}$, Larissa M. Scalon Lemos ${ }^{3}$, Guilherme B. Braga ${ }^{4}$, Jeffrey J. Shaw ${ }^{5}$ \\ ${ }^{1}$ Department of Biological Science, University of State of Mato Grosso, Cáceres, Mato Grosso, Brazil \\ ${ }^{2}$ Department of Parasitology, Institute of Animal Biology, University of Campinas, Campinas, Brazil \\ ${ }^{3}$ Department of Nursing, University of State of Mato Grosso, Cáceres, Mato Grosso, Brazil \\ ${ }^{4}$ Faculty of Veterinary Medicine, University of São Paulo, São Paulo, Brazil \\ ${ }^{5}$ Department of Parasitology, Institute of Biomedical Science, University of São Paulo, São Paulo, Brazil \\ *Corresponding author: p151867@dac.unicamp.br
}

Received March 09, 2014; Revised March 31, 2014; Accepted April 07, 2014

\begin{abstract}
A total of 1528 stool samples were examined during a survey of intestinal parasites in 542 members of the Tapirapé ethnic group (279 females and 263 males), who live in the Brazilian Amazon region of Mato Grosso. Overall, 542 individuals from six indigenous villages were enrolled of whom 45 (8.3\%) were positive for Hymenolepis nana based on analysis by microscopy of fecal concentrates. $H$. nana was more prevalent in male individuals (77.8\%) as compared to females (22.2\%). Moreover, males aged under 15 years have been associated with positivity for $H$. nana $(P=0.02)$. This study is the first report of the prevalence of $H$. nana in members of the indigenous Tapirapé ethnic group from the Brazilian Amazon.
\end{abstract}

Keywords: hymenolepis nana, prevalence, indigenous, brazilian amazon

Cite This Article: Antonio F. Malheiros, Patrick D. Mathews, Larissa M. Scalon Lemos, Guilherme B. Braga, and Jeffrey J. Shaw, "Prevalence of Hymenolepis nana in Indigenous Tapirapé Ethnic Group from the Brazilian Amazon.” American Journal of Biomedical Research, vol. 2, no. 2 (2014): 16-18. doi: 0.12691/ajbr-2-2-1.

\section{Introduction}

Hymenolepis nana is cosmopolitan in its distribution, but is more common in warm climates. H. nana is the most prevalent human-infecting tapeworm worldwide and in Brazilian communities. $H$. nana is easily transmitted directly from individual to individual. Although $H$. nana has a short life span, it is easily renewed by new generations of $H$. nana as they complete their life cycle only in human intestine [1,2]. Mild infestation with $H$. nana are asymptomatic, but heavy infestation cause abdominal pain, diarrhea, headache and dizziness among other symptoms [1,3].

Although there are several surveys for $H$. nana infection in human worldwide [4,5] information on indigenous communities is still scarce and, to our knowledge, nothing is known about $H$. nana prevalence in the indigenous group Tapirapé in Brazil. The present study reports the prevalence of $H$. nana in 542 indigenous from Confresa, (western Brazil), the region with the highest number of indigenous groups in Brazil.

\section{Materials and Methods}

The study was carried out in the Tapirapé community, situated $30 \mathrm{~km}$ from the Confresa municipality, state of Mato Grosso, Brazil. The indigenous reserve is located in Legal Amazonia and inhabited by 542 members of the
Tapirapé ethnic group. The members of this tribe have many free roaming animals including dogs, cats, chickens, and pigs. The principal source of protein for this population is derived from fishing and hunting animals such as the paca, agouti, anteater, tortoise, capuchin monkey, deer, armadillo, tapir, mallard, and curassow. Piped water is drawn from nearby rivers and is delivered to every household, but it is neither filtered nor chlorinated. There is a general lack of adequate sanitation; only one public latrine is available for the entire village; however, this latrine is not used by all the villagers.

A total of 1.528 stool specimens (279 from females and 263 from males) were collected during July 2008 to January 2010 and the concentrates obtained by the techniques of Hoffmann \& Ritchie $[6,7,8]$ were examined by light microscopy (x400). The stools specimens were collected on four occasions. These collection times occurred in each of the two main climatic seasons in the Amazon region (comprising the rainy and dry periods). The consistency (form, softness, loose, and watery) of all fecal samples was noted on collection. Demographic data and clinical information were recorded for all members of the tribe. The research was approved by the Ethics Committee of the Institute of Biomedical Sciences of the University of São Paulo, and consent was obtained from all human adult participants and from parents or legal guardians of minors according to National Committee for Ethics in Research (CONEP-120/2008).

The association of presence of $H$. nana eggs with age (young or adult), sex (male or female), diarrhea and 
abdominal pain was analyzed using Pearson's chi-square test and Fisher's exact tests. Differences were considered statistically significant when $P<0.05$. Statistical analyses were performed using SPSS 15.0 (Statistical Package for Social Science (SPSS) Inc.).

Table 1. Prevalence of $H$. nana in members of the indigenous Tapirapé from the Brazilian Amazon

\begin{tabular}{|c|c|c|c|c|}
\hline \multirow[t]{2}{*}{ Gender and age group } & \multirow[t]{2}{*}{ Individuals examined } & \multicolumn{3}{|c|}{ H. nana } \\
\hline & & Positive & $\%$ & $P$-value \\
\hline Females $(<15$ yr old $)$ & 126 & 7 & 5.6 & 0.02 \\
\hline Males ( $<15$ yr old) & 161 & 30 & 18.6 & \\
\hline Females (> 15 yr old) & 153 & 3 & 1.9 & 0.34 \\
\hline Males (> 15 yr old) & 102 & 5 & 4.9 & \\
\hline Total & 542 & 45 & 8.3 & \\
\hline
\end{tabular}

\section{Results}

Overall, 542 individuals from six indigenous villages were enrolled of whom 45 (8.3\%) were positive for $H$. nana based on microscopy of fecal concentrates (Figure 1). Hymenolepiasis was more common in males (77.8\%) than females $(22.2 \%)(P<0.05)$. Males being under 15 years of age were associated with positivity for $H$. nana $(P=$ 0.02) (Table 1).

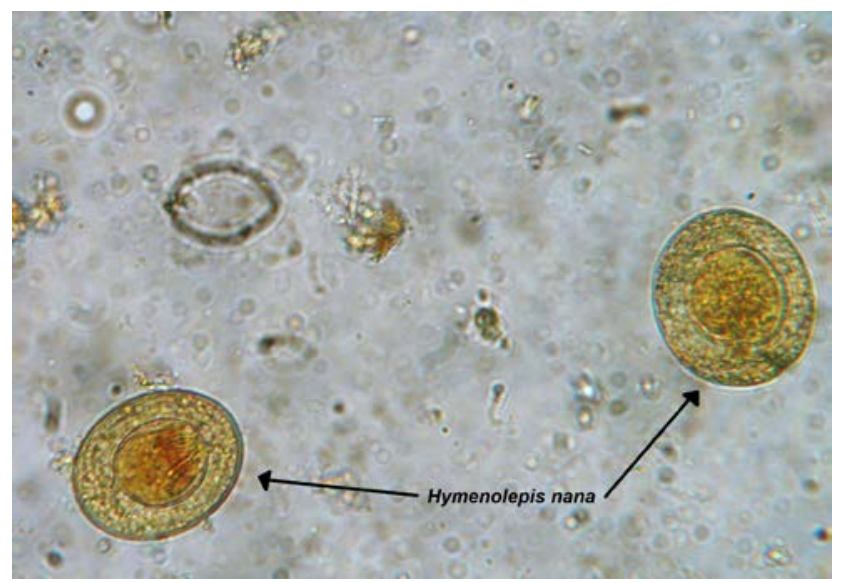

Figure 1. Eggs of H. nana examined in fecal concentrates observed by light microscopy (x400)

For a total of 45 individuals infested with hymenolepiasis symptoms such as diarrhea, abdominal pain were reported (Table 2). Other symptoms associated with $H$. nana infestation were weakness, headache and vomiting. Significant association with diarrhea was noted in individuals infected with $H$. nana $(P<0.05)$.

Table 2. Symptoms associated with $H$. nana infestation in members of the indigenous Tapirapé from the Brazilian Amazon

\begin{tabular}{|c|c|c|}
\hline of the indigenous Tapirapé from the Brazilian Amazon \\
\hline Symptoms & Individual infected (n=45) & $P$-value \\
\hline Diarrhea (\%) & $88.8(40 / 45)$ & 0.001 \\
\hline Abdominal pain (\%) & $20.0(9 / 45)$ & 0.632 \\
\hline Headache (\%) & $11.1(5 / 45)$ & 0.742 \\
\hline Vomiting (\%) & $4.4(2 / 45)$ & 0.965 \\
\hline
\end{tabular}

\section{Discussion}

Currently in Brazil important social problems directly impact in quality restrictions of public health. These problems contribute to an increased incidence of infectious and parasitic diseases, especially in populations without access to adequate sanitation, revealing the degree of environmental contamination by potential human pathogens [9]. Indeed, previous studies on intestinal parasite in Brazil have shown that these parasites are important causes of morbility among indigenous groups of Amazonia [10]. However, this is the first epidemiological study of $H$. nana in members of the indigenous Tapirapé ethnic group from the Brazilian Amazon region.

The infection rate with $H$. nana in the indigenous Tapirapé was high (8.3\%). The rate of infestation in the present study is similar to the reported in other studies in indigenous communities in Brazil, for instance in Suruí Indians (29.5\%) and in the ethnic group Karitiana (10.8\%) from State of Rondônia, in Maxakali Indians, from State of Minas Gerais (18.16\%), in members of the ethnic group Kaigàng from State of Pará (31.7\%) and in children from the Xingu Indian Reservation (28.5\%) [10,11,12,13,14]. Our results are also in agreement with studies performed in other parts of the world $[15,16]$.

This high prevalence of infestation in the present study could be related to a number of factors such as poor hygiene, inadequate sanitation, overcrowding (approximately 20 people per household), low education, and low socioeconomic status [9,17]. Another important factor which affects the prevalence of $H$. nana is the presence of asymptomatic people in the community (8\% approximately) who can be considered as the main source of infection through continuously excreting the eggs with their stools $[1,2]$. It is known, that in natural situations the great majority of infestation occur as a result of fecal contamination of food or water by humans, usually children, excreting viable eggs $[2,18]$.

In the present study a relationship between sex of the host and $H$. nana infestation was calculated and it was observed that in 263 male, 35 (13.3\%) were infested with $H$. nana and in 279 female, 10 (3.6\%) were infested with the same parasite. The results described here are in accordance with Tasawar et al. [3] who reported higher prevalence in children-males $(2.1 \%)$ than in females (1.4\%) between the ages of 4 days to 10 years in the city of Multan, Pakistan. Huda-Taher [19] reported that the individual males between ages of 1-5 years were mainly infested (70\%) than female (30\%) in Abu-Ghraib city, Iraq, and Diaz et al. [16] reported, that in children of Yukpa ethnia in Toromo, Zulia State, Venezuela, males $(85.7 \%)$ were mostly infect by $H$. nana than females (80.1\%). According to Washburn et al. [20] the heterogeneous nature of sex chromosomes in males causes sex differences in parasite resistance and thus sex steroids may directly affect parasites growth, development and may influence immune response. Indeed, levels of immunoglobulins, including IgG, IgM, and IgA are higher in females than in males [21]. Furthermore, Matsuzawa et al. [22] suggest that the expulsion of Vampirolepis nana is closely associated with the appearance of parasite-specific IgA. 
Infestation was more common in children than in adults and was often found within family. Similar prevalence of these infections have been reported in other countries $[16,17,18]$. It is known that children are more susceptible to infection parasites as compared to young and elderly humans. Moreover, $H$. nana infestation rates tend to be high in regions with high temperature and low rain fall, and our place of study lies within such an environment because the climate in the region of this study is tropical humid with average annual temperature of $29.6^{\circ} \mathrm{C}$ with shortage of rainfall during the dry season (April to October).

\section{Conclusion}

Understanding the prevalence of intestinal parasites, such as hymenolepiasis, in endemic areas may contribute to a better knowledge of the risk factors for infestation in different ecological situations. Because hymenolepiasis is apparently transmitted fecal-orally and is very common, this parasite appears to be an appropriate indicator for the overall level of intestinal parasitism in different populations. Therefore, data on hymenolepiasis could be helpful in elaborating and evaluating intervention methods to reduce the burden of intestinal parasites in indigenous communities from Brazilian Amazon.

\section{Acknowledgements}

The authors thank the Tapirapé for their hospitality and support in all phases of the study. This research was financially supported by the Brazilian Ministry of Health FUNASA, Foundation for Research of the State of Mato Grosso - FAPEMAT and the Brazilian Research Council - CNPq for a postdoctoral fellowship to Antonio Francisco Malheiros.

\section{References}

[1] Mirdha B.R., Samantray J.C., Hymenolepis nana: A common cause of pediatric diarrhoea in urban slum dwellers in India, J. Tropi. Pediatr., 2002, 48: 330-334.

[2] WHO., Intestinal protozoan and helminthic infections. Report of a WHO Scientific Group. WHO TRS., 1981, 666: 86.

[3] Tasawar Z., Gul S., Muhammad A.B., Arif M., Prevalence of Hymenolepis nana in human beings in and around MultanPakistan, Pak. J. Life Soc. Sci., 2004, 2: 62-64.

[4] Chero J.C., Saito M., Bustos J.A., Blanco E.M., Gonzalvez G., Garcia H.H., Hymenolepis nana infection: symptoms and response to nitazoxanide in field conditions, Trans. R. Soc. Trop. Med. Hyg., 2007, 101: 203-205.

[5] Sadaf H.S., Khan S.S., Kanwal N., Tasawer B.M., Ajmal S.M., A review on diarrhoea causing Hymenolepis nana dwarf tapeworm, I. R. J. P., 2013, 4: 32-35.
[6] Faust E.C., Sawitz W., Tobie J., Odom V., Peres C., Lincicome D.R., Comparative efficiency of various technics for the diagnosis of protozoa and helminths in feces, J. Parasitol., 1939, 25: 241-262.

[7] Utzinger J., Botero-Kleiven S., Castelli F., Chiodini P.L., Edwards H., Köhler N., Gulletta M., Lebbad M., Manser M., Matthys B., N’Goran E.K., Tannich E., Vounatsou P., Marti H., Microscopic diagnosis of sodium acetate-acetic acid-formalin fixed stool samples for helminths and intestinal protozoa: a comparison among European reference laboratories, Clin. Microbiol. Infect., 2010, 16: 267-273.

[8] Malheiros A.F., Stensvold R.C., Graham C.C., Braga G.B., Shaw J.J., Molecular characterization of Blastocystis obtained from members of the Indigenous Tapirapé ethnic group from the Brazilian Amazon region, Brazil, J. Trop. Med. Hyg., 2011, 85: 1050-1053.

[9] Brasil., Ministério da Saúde. Organização Pan-Americana da Saúde. Avaliação de impacto na saúde das ações de saneamento: marco conceitual e estratégia metodológica. Brasília, Ministério da Saúde., 2004, 10: 83-96.

[10] Palhano-Silva C.S., Araújo A.J.G., Lourenço A.E.P., Bastos O.M.P., Santos R.V., Coimbra C.E.A., Intestinal parasitic infection in the Suruí indians, Brazilian Amazon, Interciencia., 2009, 34: 259-264.

[11] Assis E.M., Olivieria R.C., Moreira L. E., Pena J.L., Rodrigues L.C., Machado-Coelho G.L.L., Prevalence of intestinal parasites in the Maxakali indigenous community in Minas Gerais, Brazil, 2009, Cad. Saúde Pública., 2013, 29: 681-690.

[12] Ferrari J.O., Ferreira M.U., Camargo L.M.A., Ferreira C.S., Intestinal parasites among Karitiana Indians from Rondônia State, Brazil, Rev. Inst. Med. Trop. Sao Paulo., 1992, 34: 223-225.

[13] Toledo M.J.O., Paludetto A.W., Moura F.T., Nascimento E.S., Chaves M., Araujo S.M., Mota L.T., Evaluation of enteroparasite control activities in a Kaigàng community of Southern Brazil, Rev. Saúde. Publ., 2009, 34: 981-990.

[14] Escobar-Pardo M.L., De Godoy A.P., Machado R.S., Rodriguez D., Fagundes N.U., Kawakami E., Prevalence of intestinal parasitoses in children at the Xingu Indian Reservation, J. Pediatr., 2010, 86: 493-496.

[15] Menghi C.I., Iuvaro F.R., Dellacasa M.A., Gatta C.L., Survey of intestinal parasites among an aboriginal community in Salta, Medicina., 2007, 67: 705-708.

[16] Díaz A.I., Rivero R.Z., Bracho M.A., Castellanos S.M., Acurero E., Calchi L.M., Atencio T.R., Prevalence of intestinal parasites in children of Yukpa ethnia in Toromo, Zulia State, Venezuela, Rev Méd Chile., 2006, 134: 72-78.

[17] Al-Shammari S.K.T., El-Khwasky F.G.A., Intestinal parasitic diseases in Riyadh, Saudi Arabia: prevalence, socio demographic and environmental associates, Trop. Med. Int. Health., 2001, 6: 184-189.

[18] Mason P.R., Patterson B.A., Epidemiology of Hymenolepis nana infections in primary school children in urban and rural communities in Zimbabwe, J. Parasitol., 1994, 80: 245-250.

[19] Huda-Taher A.L.M., Prevalence of Hymenolepis nana Infections in Abu-Ghraib City /Baghdad/Iraq, Iraqi Postgrad. Med. J., 2012, 11: 581-584.

[20] Washburn T.C., Medaris D.N., Childs B., Sex differences in susceptibility of infections, Pediatrics., 1965, 35: 57-64.

[21] Daniels C.W., Belosevic M., Serum antibody responses by male and female $C_{5} 7_{\mathrm{B}} 6$ mice infected with Guard moors, Clin. Exp. Immunol., 1994, 97: 424-429.

[22] Matsuzawa K., Abe M., Shirakura T., Zhao W.H., Nakamura F., Spontaneous worm expulsion and intestinal IgA response in mice infected by Vampirolepis nana, Parasitol. Int., 2008, 57: 512-514. 